6 Kinlen LJ. Can paternal preconceptional radiation account for the increase of leukaemia and non-Hodgkin's lymphoma in Seascale? BMF 1993;306:1718-21.

7 Gardner MJ, Smee MP, Hall AJ, Powell CA, Downes S, Terrell JD. Results of case-control study of leukaemia and lymphoma among young people near Sellafield nuclear plant in west Cumbria. BMF 1990;300:423-9.

8 Draper GJ, Sanders BM, Brownbill PA, Hawkins MM. Patterns of risk of hereditary retinoblastoma and applications to genetic counselling. Brf Cancer 1992;66:211-9.

9 Morris JA, Butler R, Flowerdew R, Gatrell AC. Retinoblastoma in children of former residents of Seascale. BMf 1993;306:650.

10 Sanders BM, Draper GJ, Kingston JE. Retinoblastoma in Great Britain 1969-80: incidence, treatment and survival. Brf Ophthalmol 1988;72:576-83.
11 Parkin DM, Stiller CA, Draper GJ, Bieber CA. The international incidence of childhood cancer Int $\mathcal{f}$ Cancer 1988;42:511-20.

12 Berkow RL, Fleshman JK. Retinoblastoma in Navajo Indian children. Am $\mathrm{f}$ Dis Child 1983;137:137-8.

13 Bunin GR, Meadows AT, Emanuel RS, Buckley JD, Woods WG, Hammond GD. Pre and post conception factors associated with sporadic heritable and non-heritable retinoblastoma. Cancer Res 1989;49:5730-5.

14 Bithell JF, Stewart AM. Pre-natal irradiation and childhood malignancy: a review of British data from the Oxford survey. $\mathrm{Br} .7$ Cancer 1975;31:271-87.

15 Draper GJ, Kendall GM, Muirhead CR, Sorahan T, Fox AJ, Kinlen LJ. Cancer in the children of radiation workers. Radiological Protection Bulletin 1992;129:10-4.

\title{
Spinal cord stimulation and pain relief
}

\author{
Why it works is poorly understood
}

The "gate" theory of pain, announced to a wide audience by Melzack and Wall in $1965,{ }^{1}$ profoundly changed how doctors and neuroscientists thought about the treatment of pain. The older, "classical" hypothesis of direct pain pathways had led doctors to think in terms of interrupting pain pathways and resulted in the treatments of rhizotomy, cordotomy, and thalamotomy. These surgical interruptions relieved some patients' pain, but each had substantial unwanted effects.

Melzack and Wall's gate theory presented a dynamic conception of the perception of pain and immediately suggested two new treatments to relieve pain: transcutaneous electrical nerve stimulation, and the so called "dorsal column" stimulation. Transcutaneous electrical nerve stimulation is widely used in pain clinics and in disciplines as diverse as obstetrics and dentistry.

Dorsal column-now more accurately referred to as spinal cord-stimulation has had a chequered history. The initial report of pain relief with dorsal column stimulation by Shealy et alin $1967^{2}$ evoked considerable interest. By the mid1970s many spinal cord stimulators had been implanted somewhat indiscrimately.

The initial reports of pain relief were encouraging, but for many patients the benefits seemed short lived. There were many reasons for this. As often occurs with the introduction of a new technique, criteria for selecting patients were virtually non-existent. Double blind controlled studies were impossible because it was soon recognised that the response evoked by the stimulation, usually a tingling sensation, had to be perceived as in the painful area for the technique to work. There were serious problems with the stimulation equipment: fractured wires; defective receivers, antennas, and transmitters; movement of the electrode; and connector faults all contributed to the failure rate. Most importantly, however, patients were often not followed up regularly, and failures of equipment went undetected.

Gradually neurosurgeons lost their initial enthusiasm for spinal cord stimulation, and only a few centres used the technique, although concentrating activity in fewer centres probably resulted in better selection of patients. The equipment manufacturers considerably improved the design of wire leads, connectors, and electrodes. Studies were undertaken which, although uncontrolled, at least had assessments made by observers other than the surgeon who had implanted the stimulator. These studies suggested that spinal cord stimulation with proper following could provide considerable relief to between half and three quarters of patients with chronic intractable pain. ${ }^{3}$ When these patients have often tried everything from faith healing to drugs and destructive surgery without relief of pain the results are encouraging and for some patients spectacular.
In the past 20 years other uses have been developed for spinal cord stimulation. As early as 1976 Cook et al reported that pain associated with peripheral vascular disease could be relieved by spinal cord stimulation. ${ }^{4}$ Mannheimer and his colleagues used transcutaneous electrical nerve stimulation to treat angina ${ }^{5}$ and, encouraged by the results with this technique, used spinal cord stimulation for those patients who had difficulty using the apparatus. ${ }^{6}$

While the diverse clinical applications of spinal cord stimulation were developing, physiologists greatly increased our knowledge of the pathways and transmitters involved in the perception of pain. ${ }^{7}$ Unfortunately, we still do not understand the mechanisms by which spinal cord stimulation affects perception of pain. We have a technique that we believe considerably benefits patients with intractable pain, but we have little idea of how it works. Understandably, there is some unease about using a technique whose basic mechanisms are not understood. This is particularly true when the technique involves the use of "electricity" on the nervous system.

The paper of Mannheimer and his colleagues in this issue is particularly welcome ( $p$ 477). ${ }^{8}$ The authors' careful investigations into the physiological changes in cardiac function during spinal cord stimulation for intractable angina are part of continuing efforts by this group to understand the mechanisms entailed in the relief of the pain of angina.

A natural anxiety exists that the electrical control of pain may mask "the protective warning" that angina presents to the patient, but should it be found that stimulation improves function this fear well be allayed, despite the lack of full understanding of the mechanisms of action.

E S WATKINS

Professor

T H KOEZE

Senior lecturer

Neurosurgical Unit,

Department of Neurosurgery,

Royal London Hospital,

London E1 1BB

1 Melzack R, Wall PD. Pain mechanisms: a new theory. Science 1965;150:971-9.

2 Shealy CN, Mortimer JT, Reswick JB. Electrical inhibition of pain by stimulation of the dorsal columns. Anesth Analg 1967;46:489-91.

Koeze TH, Williams AC de C, Remain S. Spinal cord stimulation and relief of chronic pain. 7 Neurol Neurosurg Psychiatry 1987;50:1424-9.

4 Cook AW, Oygar A. Baggenstos P, Pacheco S, Kleriga E. Vascular disease of extremities: electrical stimulation of spinal cord and dorsal roots. N Y State 7 Med 1976;76:366-8

Mannheimer $C$ Cans stimulation in

stimulation in severe angina pectoris. Eur Heart $f$ 1982;3:297-302. annheimer C, Augustinsson L-E, Carlsson C-A, Manhem
electrical stimulation in severe angina. Br Heart f 1988;59:56-61

electrical stimulation in severe angina. Br Heart $\mathcal{f}$ 1988;59:56-61
Wall PD, Melzack R, eds. Textbook of Pain 2nd ed. Edinburgh: Churchill Livingstone, 1989.

7 Wall PD, Melzack R, eds. Textbook of Pain 2nd ed. Edinburgh: Churchill Livingstone, 1989. 8 Mannheimer C, Eliasson T, Andersson B, Bergh C-H, Augustinsson L-E, Emanuelsson $\mathrm{H}$, et al.
Effects of spinal cord stimulation in angina pectoris induced by pacing and possible mechanisms of action. BMf 1993;307:477-80. 